\title{
Sleeve lung resection for lung cancer: Analysis according to the type of procedure
}

\author{
Kazumichi Yamamoto, MD, ${ }^{a}$ Yoshihiro Miyamoto, MD, ${ }^{a}$ Akihiro Ohsumi, MD, ${ }^{b}$ Fumitsugu Kojima, MD, ${ }^{a}$ \\ Naoko Imanishi, MD, ${ }^{a}$ Katsunari Matsuoka, MD, ${ }^{a}$ Mitsuhiro Ueda, MD, and Chikuma Hamada, $\mathrm{PhD}^{\mathrm{c}}$
}

From the Department of Thoracic Surgery, National Hospital, Organization Himeji Medical Center, ${ }^{a}$ Himeji, Japan; Department of Thoracic Surgery, Tenri Hospital, ${ }^{\mathrm{b}}$ Tenri, Japan; and Faculty of Engineering, Tokyo University of Science, ${ }^{\mathrm{c}}$ Tokyo, Japan.

This study was sponsored in part by the Cancer Research Fund of the Hyogo Prefecture Health Promotion Association.

Received for publication Nov 5, 2007; revisions received Feb 23, 2008; accepted for publication May 4, 2008.

Address for reprints: Kazumichi Yamamoto, MD, Department of Thoracic Surgery, National Hospital, Organization Himeji Medical Center, Honmachi 68, Himeji, Hyogo, 670-8520, Japan (E-mail: granada@d3. dion.ne.jp).

J Thorac Cardiovasc Surg 2008;136:134956

$0022-5223 / \$ 34.00$

Copyright $\odot 2008$ by The American Association for Thoracic Surgery

doi:10.1016/j.jtcvs.2008.05.018
Objective: Although sleeve lobectomy for lung cancer is widely accepted as an alternative to pneumonectomy, its use remains controversial. This study aimed to evaluate the surgical results after sleeve lung resection and to compare the outcomes of different procedural approaches.

Methods: The medical records of 201 patients who underwent sleeve lung resection for lung cancer were retrospectively reviewed. Three groups were compared: a standard group (lobectomy or bilobectomy; $\mathrm{n}=173$ ), limited group (segmentectomy; $\mathrm{n}=8$ ), and extended group (lobectomy or bilobectomy plus segmentectomy; $\mathrm{n}=20$ ).

Results: Three patients died postoperatively (1.4\%). Anastomotic complications occurred in 7 patients (3.4\%; fistula in 4 patients, stenosis in 3 patients), 6 of whom were successfully treated surgically or conservatively. Five-year overall and disease-free survivals were $57.8 \%$ and $50.3 \%$, respectively. Sites of recurrence included anastomotic sites $(\mathrm{n}=5)$, ipsilateral thorax $(\mathrm{n}=11)$, mediastinum $(\mathrm{n}=$ $10)$, and distant sites $(n=43)$. Multivariate analysis showed that the influence of nodal status on both overall and disease-free survival was significant. All patients in the limited group but 1 who underwent lobectomy for recurrence in another lobe are alive without recurrence. Three patients in the extended group experienced distant metastasis, but none experienced local recurrences. Multivariate analysis showed extended group-to-standard group hazard ratios of 0.53 (95\% confidence interval, $0.23-1.23$ ) for overall survival and 0.48 (95 confidence interval, $0.22-1.05$ ) for disease-free survival.

Conclusion: Sleeve lung resection can achieve local tumor control and long-term survival with low mortality and few anastomotic complications. Nodal status significantly affects long-term survival. Limited and extended resections are also feasible with local and long-term results comparable to those of standard sleeve lobectomy.

A lthough sleeve lobectomy for primary lung cancer was initially used to avoid pneumonectomy in patients with impaired pulmonary function, recent studies suggest that it is the alternative of choice to pneumonectomy even for patients with sufficient pulmonary reserve. ${ }^{1-5}$

However, the indications for sleeve lobectomy or pneumonectomy are still controversial and depend on each surgeon. In fact, bronchoplastic procedures are performed in $3 \%$ to $19 \%$ patients who undergo lung resection for primary lung cancer. ${ }^{2,3,6-8}$

We used bronchoplastic procedures when technically and oncologically possible to preserve lung parenchyma in patients with primary lung cancer, avoid pneumonectomy in patients with locally advanced tumor, and avoid lobectomy in patients with early endobronchial tumor.

The purpose of this study is to describe our single-institution experience of sleeve lung resection for primary lung cancer and to assess the surgical results of 3 approaches: standard (lobectomy or bilobectomy), limited (segmentectomy), and extended (lobectomy or bilobectomy plus segmentectomy). 


\section{Abbreviation and Acronym}

$\mathrm{CI}=$ confidence interval

\section{Materials and Methods}

Of 2296 patients who underwent operation for primary lung cancer between 1986 and 2006 in our institution, the National Hospital Organization, Himeji Medical Center, 201 (8.7\%) underwent sleeve lung resection. The medical records of these patients were reviewed retrospectively. Those who underwent carinal resection or wedge resection of the bronchus were excluded. The data were collected from hospital charts, referring physicians, and the patients or the patients' family. The protocol of this retrospective study was approved by the institutional ethics committee of the National Hospital Organization, Himeji Medical Center. Individual consent of patients was waived because individual patients are not identified.

Sleeve lung resection was always applied to preserve as much lung parenchyma as possible when the tumor and involved lymph nodes could be completely resected by the technique. Three types of sleeve lung resection were performed for maximum preservation of lung parenchyma: sleeve lobectomy or bilobectomy as a standard procedure for central tumors located at the origin of a lobar bronchus (standard group), sleeve segmentectomy for early endobronchial tumor at the origin of a segmental bronchus to avoid lobectomy (limited group), and sleeve lobectomy or bilobectomy plus segmentectomy for a locally advanced tumor that could not be resected by standard sleeve lobectomy or bilobectomy (extended group).

Standard surgical technique was used for lobectomy and segmentectomy until the bronchus was encountered. Mediastinal lymph node dissection was routinely performed before the bronchus was cut to avoid further dissection around the bronchus after completion of the bronchial anastomosis. Circumferential bronchial resection was performed to create a sufficient margin around the tumor bed. Frozen sections of the resected margins were examined to ensure complete resection. Anastomosis was performed with interrupted sutures using 3-0 Vicryl (Ethicon, Somerville, NJ) in end-to-end fashion or telescope fashion. All the knots were tied outside the bronchus. Concomitant wedge or sleeve resection of the pulmonary artery was performed when necessary using 5-0 Prolene (Ethicon). Pedicled intercostal muscle flap or pericardial fat tissue was not routinely used.

Patients were extubated in the operating room or intensive care unit after the procedure. In addition to standard postoperative management for conventional lung resection, bronchofiberscopy to clear bronchial secretion was aggressively performed when necessary. Bronchofiberscopy was routinely performed 3 to 4 weeks after the operation to observe the condition of the anastomosis. After discharge, bronchofiberscopy was planned when stenosis or recurrence at the anastomotic site was suspected.

Resection was considered complete when the resection margins were free of disease. Pathologic staging was performed according to the New International Staging System for Lung Cancer. ${ }^{9}$

For follow-up, patients were observed from the date of the operation to the time of death or March of 2007. Operative mortality was defined as death within 30 days after the operation or in-hospital death without discharge. The site of recurrence was classified as anastomotic, within the ipsilateral thorax, mediastinal, or distant.
The cause of death was classified as local recurrence, distant metastasis, second primary lung cancer, other cause, or unknown. Survival was calculated, and adverse events including all-cause death were evaluated.

Survivals were calculated by life-table analysis. Kaplan-Meier curves were plotted and compared using the log-rank test for univariate analysis. The results of the multivariate analysis of independent prognostic factors and type of procedure were assessed using the Cox proportional hazards model with backward selection.

\section{Results}

\section{Patient Characteristics}

A total of 201 patients (187 male and 14 female; mean age, $66.8 \pm 8.3$ years [range, 28-82 years]) underwent sleeve lung resection for primary lung cancer during the 21-year period of the study. The mean follow-up period was 50 months (range, 0-189 months).

Twenty-two patients received preoperative induction therapy. Twenty patients received 1 to 2 cycles of chemotherapy. One patient received concurrent chemoradiotherapy ( 2 cycles of chemotherapy plus 40 Gy of radiotherapy), and 1 patient received 20 Gy of radiotherapy preoperatively.

Histology identified 163 squamous cell carcinomas (81\%), 26 adenocarcinomas (12\%), 2 adenosquamous cell carcinomas $(0.9 \%)$, and 10 non-adeno, nonsquamous cell carcinomas (3 large cell carcinomas, 3 carcinoids, 2 small cell carcinomas, 1 adenoid cystic carcinoma, and 1 other). Fifty-four patients (26\%) had T1 disease, 108 patients (53\%) had T2 disease, 27 patients (13\%) had T3 disease, and 11 patients $(5 \%)$ had T4 disease. A total of 103 patients $(51 \%)$ had N0 disease, 56 patients $(27 \%)$ had N1 disease, and 42 patients $(20 \%)$ had N2 disease. Resection was incomplete in 11 patients $(5.4 \%)$ who also had a positive bronchial margin.

\section{Type of Resection}

Table 1 shows the type of procedure and concomitant vascular resection. Standard procedures (sleeve lobectomy or bilobectomy) were performed in 173 patients (standard group), limited procedures (sleeve segmentectomy) were performed in 8 patients (limited group), and extended procedures (sleeve lobectomy or bilobectomy plus segmentectomy) were performed in 20 patients (extended group). Concomitant sleeve or wedge resection of the pulmonary artery for invasion of the tumor was performed in 49 patients (sleeve in 33 patients, wedge in 16 patients).

\section{Operative Morbidity and Mortality}

Table 2 shows the operative morbidity and mortality. A total of 105 complications occurred in 80 patients (39\%). In this series, 51 patients had prolonged air leak more than 7 days, but only 2 of these patients required re-thoracotomy. Anastomotic complications occurred in 7 patients (fistula in 4 patients, stenosis in 3 patients). All 4 patients with 
TABLE 1. Types of resection

\begin{tabular}{|c|c|c|c|}
\hline \multirow[b]{2}{*}{ Type of procedure } & & \multicolumn{2}{|c|}{ Vascular resection } \\
\hline & & Sleeve & Wedge \\
\hline Standard group & 173 & & \\
\hline \multicolumn{4}{|l|}{ Right } \\
\hline Upper lobe & 70 & 4 & 7 \\
\hline Middle lobe & 1 & & \\
\hline Lower lobe & 9 & & \\
\hline Upper-middle lobe & 8 & 2 & \\
\hline Middle-lower lobe & 22 & 1 & \\
\hline \multicolumn{4}{|l|}{ Left } \\
\hline Upper lobe & 49 & 16 & 7 \\
\hline Lower lobe & 14 & 1 & 2 \\
\hline Limited group & 8 & & \\
\hline \multicolumn{4}{|l|}{ Right } \\
\hline Middle lobe, S6 & 2 & & \\
\hline S6 & 1 & & \\
\hline \multicolumn{4}{|l|}{ Left } \\
\hline Lingula & 1 & & \\
\hline Upper division of upper lobe & 3 & & \\
\hline S6 & 1 & & \\
\hline Extended group & 20 & & \\
\hline \multicolumn{4}{|l|}{ Right } \\
\hline Upper lobe, S6 & 3 & 1 & \\
\hline Upper-middle lobe, S6 & 2 & 1 & \\
\hline \multicolumn{4}{|l|}{ Left } \\
\hline Upper lobe, S6 & 8 & 7 & \\
\hline Lingula, lower lobe & 7 & & \\
\hline Total & 201 & 33 & 16 \\
\hline
\end{tabular}

TABLE 2. Postoperative complications

\begin{tabular}{lccc}
\hline \multicolumn{1}{c}{ Complications } & Morbidity & (\%) & Mortality \\
\hline Bronchial complications & & & \\
$\quad$ Anastomotic fistula & 4 & $(1.9)$ & \\
$\quad$ Anastomotic stenosis & 3 & $(1.4)$ & \\
Pulmonary complications & & & \\
$\quad$ Empyema & 6 & $(2.9)$ & \\
$\quad$ Pneumonia & 6 & $(2.9)$ & \\
Respiratory failure & 2 & $(0.9)$ & 1 \\
Interstitial pneumonia & 2 & $(0.9)$ & \\
$\quad$ Prolonged air leak $\geq 7$ d & 51 & $(25)$ & \\
$\quad$ Atelectasis requiring & 12 & $(5.9)$ & \\
$\quad$ bronchoscopy & & & \\
Cardiovascular complications & & & \\
$\quad$ Arrhythmia & 4 & $(1.9)$ & \\
$\quad$ Embolism of popliteal artery & 1 & & \\
Other complications & & & \\
$\quad$ Postoperative bleeding & 6 & $(2.9)$ & 1 \\
$\quad$ requiring re-thoracotomy & & & \\
$\quad$ Chylothorax & 6 & $(2.9)$ & \\
Horner's syndrome & 1 & $(0.4)$ & \\
$\quad$ Recurrent nerve palsy & 1 & $(0.4)$ & \\
Other in-hospital death & & & 1 \\
Total & 105 (80 patients) & & $\mathbf{3}$ \\
\hline
\end{tabular}

anastomotic fistula were treated surgically. One of these 4 patients who had empyema caused by fistula was treated by omentopexy. The other 3 patients without empyema were successfully treated surgically (pedicled muscle flap in 2 patients, completion pneumonectomy in 1 patient). Three patients experienced late anastomotic stenosis. The general condition of 1 patient was too poor to warrant further intervention, and only tracheostomy was performed to control bronchial secretion. This patient died of recurrence 30 months after surgery. The second patient underwent re-anastomosis successfully, and the third patient was successfully treated by balloon dilatation.

Three patients died postoperatively $(1.4 \%)$. One patient died on the nineteenth postoperative day from respiratory failure after the surgical procedure. Preoperative pulmonary function of this patient was low (forced expiratory volume in 1 second: $840 \mathrm{~mL}$ ) and was considered an absolute contraindication to pneumonectomy. One patient died on the thirtyeighth postoperative day from metastasis to the adrenal gland. One patient died on the third postoperative day from intrathoracic bleeding after wedge resection of the pulmonary artery.

\section{Survival}

Follow-up was completed in 194 patients (96\%). Overall 5- and 10-year survivals were $57.8 \%$ and $44.5 \%$, respectively. Disease-free survivals were $50.3 \%$ and $42.5 \%$, respectively. Tables 3 and 4 list prognostic factors investigated in this study. Significant prognostic factors in univariate analysis and type of procedure were entered into multivariate analysis, which identified nodal status as the only significant prognostic factor for both overall and disease-free survivals.

Overall 5- and 10-year survivals were $72.6 \%$ and $60.3 \%$ in patients with N0 disease, $48.9 \%$ and $35.3 \%$ in patients with $\mathrm{N} 1$ disease, and $32.9 \%$ and $19.2 \%$ in patients with N2 disease, respectively (Figure 1). Disease-free 5- and 10-year survivals were $69.6 \%$ and $60.3 \%$ in patients with N0 disease, $37.6 \%$ and $28.2 \%$ in patients with $\mathrm{N} 1$ disease, and $20.6 \%$ and $20.6 \%$ in patients with $\mathrm{N} 2$ disease, respectively (Figure 2).

\section{Sites of Recurrence and Cause of Death}

Of the 91 patients who died, death was due to lung cancer recurrence in 53 (local in 15 patients and distant in 38 patients) and second primary lung cancer in 3 . Of the 11 patients with positive bronchial margin, 6 died of lung cancer recurrence, which was at the anastomotic site in 2 of these cases.

If the data are limited to 5 years follow-up to avoid bias by the difference of follow-up period, 76 patients died and death was due to lung cancer recurrence in 49 patients (local in 15 patients and distant in 34 patients) and second primary cancer in 2 patients. Of 21 patients who died of other cause, 6 had recurrence. The first sites of recurrence for the entire 
TABLE 3. Univariate and multivariate analyses for overall survival

\begin{tabular}{|c|c|c|c|c|c|c|}
\hline \multirow[b]{2}{*}{ Risk factor } & & \multirow[b]{2}{*}{$\mathbf{n}$} & \multirow{2}{*}{$\frac{\text { Univariate analysis }}{P \text { value }}$} & \multicolumn{3}{|c|}{ Multivariate analysis } \\
\hline & & & & $P$ value & HR & $95 \% \mathrm{Cl}$ \\
\hline Gender & Male/female & $187 / 14$ & NS & & & \\
\hline Age, y & $<70 /$ more & $116 / 85$ & NS & & & \\
\hline Symptoms & No/Yes & $57 / 144$ & NS & & & \\
\hline Smoking & No/Yes & $11 / 190$ & NS & & & \\
\hline $\mathrm{FEV}_{1}$ & $\geq 70 /$ less & $122 / 79$ & NS & & & \\
\hline Neoadjuvant therapy & No/Yes & $179 / 22$ & NS & & & \\
\hline Side & Right/Left & $118 / 83$ & NS & & & \\
\hline \multirow[t]{3}{*}{ Type of procedure } & Standard/Limited/Extended & $173 / 8 / 20$ & NS & .1 & & \\
\hline & Standard/Limited & $173 / 8$ & NS & .2 & 0.32 & $0.04-2.34$ \\
\hline & Standard/Extended & $173 / 20$ & NS & .1 & 0.53 & $0.23-1.23$ \\
\hline Angioplasty & No/Yes & $152 / 49$ & NS & & & \\
\hline \multirow[t]{2}{*}{ Histology } & Squamous/Adenocarcinoma/Others & $163 / 26 / 12$ & NS & NS & & \\
\hline & Squamous/Adenocarcinoma & $163 / 26$ & .04 & NS & & \\
\hline Invaded stump & No/Yes & $190 / 11$ & .01 & NS & & \\
\hline $\mathrm{T}$ & $\mathrm{T} 1 / \mathrm{T} 2 / \mathrm{T} 3 / \mathrm{T} 4$ & $54 / 108 / 27 / 11$ & .03 & .04 & 1.31 & $1.00-1.71$ \\
\hline $\mathrm{N}$ & No/N1/N2 & $103 / 56 / 42$ & .0000 & .000 & 1.77 & $1.35-2.31$ \\
\hline M & Mo/M1 & $198 / 3$ & .0001 & .02 & 5.22 & $1.20-22.61$ \\
\hline
\end{tabular}

FEV ${ }_{1}$, Forced expiratory volume in 1 second; $H R$, hazard ratio; $C l$, confidence interval; $N S$, not significant.

group included anastomotic sites $(\mathrm{n}=5)$, ipsilateral thorax $(n=11)$, mediastinum $(n=10)$, and distant sites $(n=43)$.

\section{Analysis According to Type of Procedure}

Limited group $(n=8)$. Table 5 summarizes the patient characteristics, surgical procedures, pathologic findings, and prognosis of the limited group ( 7 men and 1 woman; mean age, 64 years [range, $28-78$ years]). Overall follow-up ranged from 13 to 127 months, with a mean of 47 months. The histologic cell type was squamous cell carcinoma in 6 patients and carcinoid in 2 patients. Complete resection was performed in all patients. Nodal stage was N0 in 5 patients, N1 in 2 patients, and $\mathrm{N} 2$ in 1 patient. There was no postoperative death, and only 1 patient developed prolonged air leak postoperatively. Only 1 patient experienced local recurrence in the ipsilateral lobe (right upper lobe), which was successfully resected

TABLE 4. Univariate and multivariate analyses for disease-free survival

\begin{tabular}{|c|c|c|c|c|c|c|}
\hline \multirow[b]{2}{*}{ Risk factor } & & \multirow[b]{2}{*}{ n } & \multirow{2}{*}{$\frac{\text { Univariate analysis }}{P \text { value }}$} & \multicolumn{3}{|c|}{ Multivariate analysis } \\
\hline & & & & $P$ value & HR & $95 \% \mathrm{CI}$ \\
\hline Gender & Male/Female & $187 / 14$ & NS & & & \\
\hline Age & $<70 /$ more & $116 / 85$ & NS & & & \\
\hline Symptoms & No/Yes & $57 / 144$ & NS & & & \\
\hline Smoking & No/Yes & $11 / 190$ & NS & & & \\
\hline $\mathrm{FEV}_{1}$ & $\geq 70 /$ less & $122 / 79$ & NS & & & \\
\hline Neoadjuvant therapy & No/Yes & $179 / 22$ & .004 & .03 & 1.84 & $1.05-3.21$ \\
\hline Side & Right/Left & $118 / 83$ & .03 & NS & & \\
\hline \multirow[t]{3}{*}{ Type of procedure } & Standard/Limited/Extended & $173 / 8 / 20$ & NS & .06 & & \\
\hline & Standard/Limited & $173 / 8$ & NS & .1 & 0.22 & $0.03-1.63$ \\
\hline & Standard/Extended & $173 / 20$ & NS & .06 & 0.48 & $0.22-1.05$ \\
\hline Angioplasty & No/Yes & $152 / 49$ & NS & & & \\
\hline \multirow[t]{2}{*}{ Histology } & Squamous/Adenocarcinoma/Others & $163 / 26 / 12$ & .0009 & NS & & \\
\hline & Squamous/Adenocarcinoma & $163 / 26$ & .0003 & NS & & \\
\hline Invaded stump & No/Yes & 190/11 & .02 & .02 & 2.27 & $1.09-4.75$ \\
\hline $\mathrm{T}$ & $\mathrm{T} 1 / \mathrm{T} 2 / \mathrm{T} 3 / \mathrm{T} 4$ & $54 / 108 / 27 / 11$ & .005 & NS & & \\
\hline $\mathrm{N}$ & N0/N1/N2 & 103/56/42 & .0000 & .000 & 1.90 & $1.49-2.42$ \\
\hline M & M0/M1 & $198 / 3$ & .02 & NS & & \\
\hline
\end{tabular}

$F E V_{1}$, Forced expiratory volume in 1 second; $H R$, hazard ratio; $C l$, confidence interval; $N S$, not significant. 


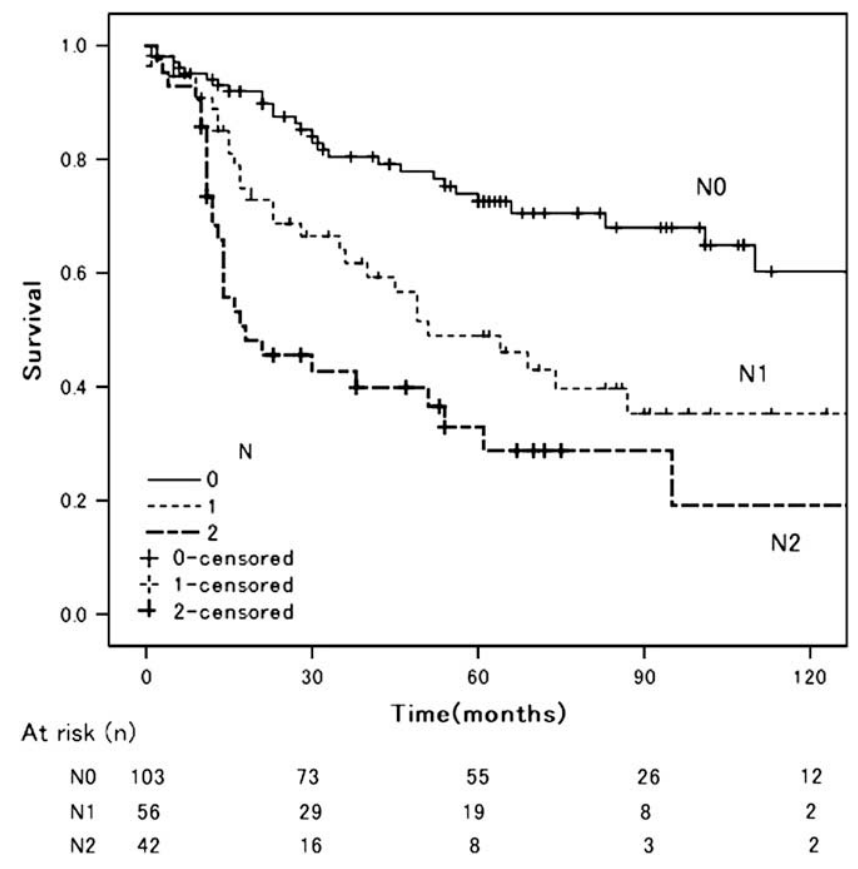

Figure 1. Life-table graph of overall survival according to nodal status. Overall 5- and 10 -year survivals were $72.6 \%$ and $60.3 \%$ in patients with NO disease, $\mathbf{4 8 . 9} \%$ and $35.3 \%$ in patients with $\mathrm{N} 1$ disease, and $32.9 \%$ and $19.2 \%$ in patients with N2 disease, respectively.

surgically. This patient died of another cause 35 months after the operation. Overall 5-year survival of this group was $83 \%$.

Extended group $(\boldsymbol{n}=20)$. Table 6 summarizes the patient characteristics, surgical procedures, pathologic findings, and prognosis of the extended group ( 20 men; mean age, 65 years [range, 49-78 years]). Overall follow-up ranged from 13 to 113 months, with a mean of 50 months. The histologic cell type was squamous cell carcinoma in 16 patients, adenocarcinoma in 3 patients, and large cell carcinoma in 1 patient. Complete resection was performed in 18 patients. Concomitant sleeve resection of the pulmonary artery was carried out in 9 patients. Nodal stage was N0 in 7 patients, N1 in 9 patients, and N2 in 4 patients.

There was no postoperative death. Two patients (numbers 8 and 17) had postoperative pneumonia and empyema. Patient number 8 experienced postoperative pneumonia followed by empyema without fistula, which was successfully treated conservatively. Patient number 17 experienced empyema caused by necrosis of the remaining right upper lobe. This patient underwent completion sleeve pneumonectomy and open thoracotomy. Omentopexy was used to close the open thoracotomy, and this patient is free from recurrence 33 months after the operation.

Overall and disease-free 5-year survivals were $67 \%$ and $65 \%$, respectively. Three patients experienced distant metas-

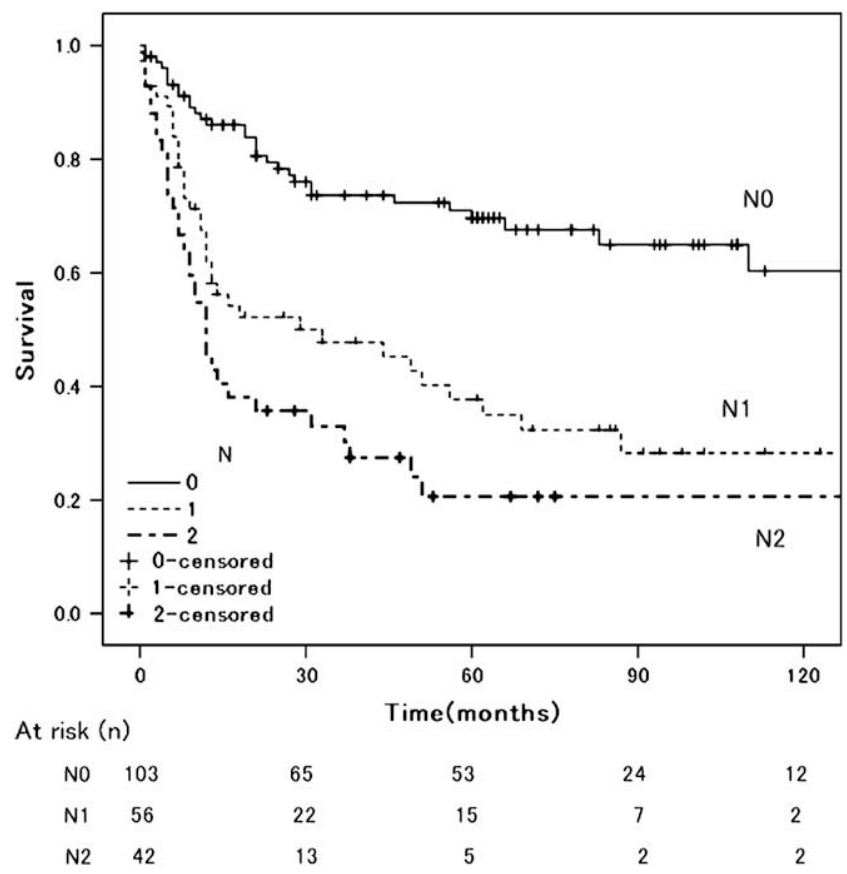

Figure 2. Life-table graph of disease-free survival according to nodal status. Disease-free 5 - and 10 -year survivals were $\mathbf{6 9 . 6 \%}$ and $60.3 \%$ in patients with NO disease, $37.6 \%$ and $28.2 \%$ in patients with $\mathrm{N} 1$ disease, and $20.6 \%$ and $20.6 \%$ in patients with $\mathrm{N} 2$ disease, respectively.

tasis, but no local recurrences have occurred. Multivariate analysis showed extended group-to-standard group hazard ratios of 0.53 (95\% confidence interval [CI], 0.23-1.23) for overall survival and 0.48 (95 CI, 0.22-1.05) for diseasefree survival.

\section{Discussion}

Currently, sleeve lobectomy is widely accepted as an alterative to pneumonectomy for centrally located lung tumors in patients with uncompromised lung function. ${ }^{1-5}$ Recent studies suggest that pneumonectomy compared with sleeve lobectomy may not increase survival, and therefore sleeve lobectomy has become the procedure of choice even in patients with N2 disease. ${ }^{1,8}$ However, each surgeon decides what the indications are for sleeve lobectomy or pneumonectomy. In fact, bronchoplastic procedures have been performed in $3 \%$ to $19 \%$ of patients who underwent lung resection for primary lung cancer. ${ }^{2,3,6-8}$ This is partly because sleeve resections are technically demanding, and there is still a fear of local recurrence.

We have used bronchoplastic procedures to preserve as much lung parenchyma as possible and avoid pneumonectomy and lobectomy. Okada and colleagues ${ }^{1,6,10}$ reported that in addition to standard sleeve lobectomy, aggressive 
TABLE 5. Characteristics of extended group

\begin{tabular}{|c|c|c|c|c|c|c|c|c|c|c|c|c|}
\hline No. & Sex & Age & Resected lung & $\begin{array}{c}\text { PA } \\
\text { resection }\end{array}$ & Histology & $\mathbf{T}$ & $\mathbf{N}$ & $\mathbf{M}$ & Complication & Recurrence & Prognosis & Cause of death \\
\hline 1 & M & 73 & Left UL S6 & Sleeve & LA & $x$ & 1 & 0 & No & No & 91 mo, alive & \\
\hline 2 & M & 66 & Right UL S6 & & SO & 2 & 2 & 0 & Prolonged air leak & Distant & $18 \mathrm{mo}$, dead & $\begin{array}{l}\text { Diastasis } \\
\text { metastasis }\end{array}$ \\
\hline 3 & $M$ & 75 & Left UL S6 & Sleeve & SO & 1 & 0 & 0 & Prolonged air leak & No & $61 \mathrm{mo}$, alive & \\
\hline 4 & $M$ & 78 & Right UL S6 & & SQ & 2 & 2 & 0 & Atelectasis & No & 67 mo, alive & \\
\hline 5 & $M$ & 66 & Left UL S6 & Sleeve & SO & 2 & 0 & 0 & Prolonged air leak & No & $61 \mathrm{mo}$, alive & \\
\hline 6 & $M$ & 68 & Left UL S6 & Sleeve & SO & 4 & 1 & 0 & Prolonged air leak & No & 85 mo, alive & \\
\hline 7 & $M$ & 67 & Left LL S4+5 & & SO & 2 & 1 & 0 & No & No & 113 mo, alive & \\
\hline 8 & M & 68 & Right UL S6 & & $A D$ & 1 & 1 & 0 & $\begin{array}{l}\text { Atelectasis, pneumonia, } \\
\text { empyema }\end{array}$ & No & $69 \mathrm{mo}$, dead & Other cause \\
\hline 9 & M & 49 & Left LL S4+5 & & SQ & 1 & 0 & 0 & No & No & 72 mo, alive & \\
\hline 10 & M & 64 & Left LL S4+5 & & SO & 2 & 1 & 0 & No & Distant & 49 mo, dead & $\begin{array}{l}\text { Diastasis } \\
\text { metastasis }\end{array}$ \\
\hline 11 & M & 76 & Left LL S4+5 & & SQ & 3 & 1 & 0 & No & No & $49 \mathrm{mo}$, dead & Other cause \\
\hline 12 & M & 51 & Left LL S4+5 & & SO & 2 & 2 & 0 & No & No & $47 \mathrm{mo}$, alive & \\
\hline 13 & M & 65 & Left UL S6 & & SO & 2 & 0 & 0 & No & No & 13 mo, dead & Other cause \\
\hline 14 & M & 61 & Left LL S4+5 & & $A D$ & 2 & 0 & 0 & No & No & 44 mo, alive & \\
\hline 15 & M & 59 & Right UL ML S6 & Sleeve & $A D$ & 2 & 1 & 0 & Prolonged air leak & Distant & 42 mo, alive & \\
\hline 16 & M & 59 & Left UL S6 & Sleeve & SQ & 2 & 2 & 0 & Prolonged air leak & No & $38 \mathrm{mo}$, alive & \\
\hline 17 & $M$ & 57 & Right UL ML S6 & Sleeve & SQ & 3 & 1 & 0 & Pneumonia, empyema & No & 33 mo, alive & \\
\hline 18 & M & 70 & Left LL S4+5 & & SO & 2 & 0 & 0 & No & No & $21 \mathrm{mo}$, dead & Other cause \\
\hline 19 & M & 67 & Left UL S6 & Sleeve & SO & 3 & 0 & 0 & No & No & 15 mo, alive & \\
\hline 20 & M & 73 & Left UL S6 & Sleeve & SO & 2 & 1 & 0 & No & No & 14 mo, alive & \\
\hline
\end{tabular}

$P A$, Pulmonary artery; $U L$, upper lobe; $L L$, lower lobe, $M L$, middle lobe; $L A$, large cell carcinoma; $S Q$, squamous cell carcinoma, $A D$, adenocarcinoma.

application of bronchoplastic procedures to avoid pneumonectomy (extended sleeve lobectomy) and sleeve segmentectomy to avoid lobectomy are feasible with good local control and long-term survival. Thus, if bronchoplastic procedures offer good surgical results or at least results equal to those of standard pneumonectomy and lobectomy, the consequent increase in preserved lung parenchyma could contribute to a better quality of life and retain the possibility of resection of a second primary lung cancer.

One of the greatest concerns for bronchoplastic procedures is its association with relatively high mortality and morbidity. In a recent meta-analysis, Ferguson and col- leagues ${ }^{4}$ reported a mean operative mortality of $4.1 \%$ (CI, $2.3 \%-5.9 \%$ ) due to sleeve lobectomy and $6.0 \%$ (CI, $1 \%-$ $11 \%$ ) due to pneumonectomy. In our series, 3 patients died postoperatively (1.4\%): One death was due to systemic metastasis, and 2 deaths were due to postoperative complications. This result was acceptable and comparable to the results of standard lobectomy because pneumonectomy was contraindicated in 1 patient.

Anastomotic complications are serious problems after bronchoplastic procedures. Anastomotic fistula or dehiscence in the early postoperative period and late anastomotic stenosis are 2 major anastomotic complications. As for early

TABLE 6. Characteristics of limited group

\begin{tabular}{|c|c|c|c|c|c|c|c|c|c|c|c|}
\hline No. & Sex & Age & Resected lung & Histology & $\mathbf{T}$ & $\mathbf{N}$ & $\mathbf{M}$ & Complication & Recurrence & Prognosis & Cause of death \\
\hline 1 & $\mathrm{M}$ & 56 & Left S4+5 & Carcinoid & 1 & 0 & 0 & No & No & $127 \mathrm{mo}$, alive & \\
\hline 2 & $M$ & 61 & Left $S 1+2+3$ & SQ & 1 & 1 & 0 & No & No & 86 mo, alive & \\
\hline 3 & $M$ & 75 & Left $S 1+2+3$ & SQ & 1 & 0 & 0 & No & No & 107 mo, alive & \\
\hline 4 & $M$ & 78 & Right S6 & SQ & 1 & 1 & 0 & No & RUL & 35 mo, dead & Other cause \\
\hline 5 & $M$ & 72 & Left S6 & SQ & 1 & 0 & 0 & Prolonged air leak & No & $60 \mathrm{mo}$, alive & \\
\hline 6 & $M$ & 72 & Left $S 1+2+3$ & SO & 1 & 0 & 0 & No & No & $41 \mathrm{mo}$, alive & \\
\hline 7 & $M$ & 71 & Right ML S6 & SO & 2 & 2 & 0 & No & No & 23 mo, alive & \\
\hline 8 & $F$ & 28 & Right ML S6 & Carcinoid & 1 & 0 & 0 & No & No & 13 mo, alive & \\
\hline
\end{tabular}

$M L$, Middle lobe; $S Q$, squamous cell carcinoma; $R U L$, right upper lobe. 
fistula or dehiscence, we recommend urgent surgical intervention before fistula progresses to empyema. In fact, all 4 patients with anastomotic fistula were successfully treated by surgical intervention. Late stenosis is another serious problem because this condition can cause repetitive obstructive pneumonia, which interferes with the patient's quality of life.

Re-anastomosis is an option if the patient's condition is not poor. However, for patients with impaired pulmonary function, surgical intervention is sometimes difficult and stent insertion, laser coagulation, or tracheostomy is a possible palliative treatment to control bronchial secretion. In our series, 6 of 7 patients with anastomotic complications were successfully managed; therefore, aggressive surgical correction is worthwhile for postoperative anastomotic problems.

Another concern for bronchoplastic procedures is the potentially increased incidence of local recurrence. The local recurrence rate is reported to be $4.5 \%$ to $22 \%$. $^{1,5,8,11}$ This variation is partly because there are differences in the definition of local recurrence. If local recurrence is defined as relapse at the anastomotic site or within the ipsilateral thorax, the local recurrence rate is $7.9 \%$ in our series, and together with mediastinal recurrence, the local recurrence rate is $12.9 \%$, which is comparable to previously reported rates. ${ }^{1,5,8,11}$

With regard to long-term survival in our series, only nodal status was identified by multivariate analysis as a significant prognostic factor in overall survival and disease-free survival. The relationship between long-term survival and nodal status has been reported. ${ }^{5,8,11,12}$ Van Schil and colleagues ${ }^{11}$ reported a significant difference in survival between patients with N0 and N1 or N2 but not N1 and N2 disease. Nevertheless, others concluded that 5-year survival in patients with $\mathrm{N} 2$ disease is close to $0 \% .^{5,8,12}$ In our series, overall 5-year survival in patients with N0, N1, and N2 is $72 \%, 48 \%$, and $32 \%$, respectively, which is comparable to the results of conventional lung resection for primary lung cancer. ${ }^{13}$ In other words, the long-term results of sleeve lung resection and conventional lung resection are comparable if the tumor and involved lymph node are properly resected. Sleeve lobectomy can thus be of the preferred procedure not only in patients with $\mathrm{N} 0$ disease but also in patients with $\mathrm{N} 1$ or $\mathrm{N} 2$ disease.

Our greatest concern is whether avoidance of pneumonectomy or lobectomy oncologically justifies aggressive application of sleeve lung resection. Okada and colleagues ${ }^{6,10}$ reported the surgical results of extended sleeve lobectomy and sleeve segmentectomy and concluded that these 2 types of atypical bronchoplastic procedures are feasible without anastomotic complications or local recurrence, and with favorable long-term survival. In our series, extended sleeve lobectomy and standard sleeve lobectomy were associated with comparable long-term survival in multivariate analysis and there was no local recurrence even in patients with N2 disease. We now prefer extended sleeve lobectomy to pneu- monectomy because it preserves lung parenchyma that improves quality of life and reduces late cardiopulmonary insufficiency. It is the preferred procedure if the tumor and involved lymph node can be resected. As for segmentectomy, the Lung Cancer Study Group concluded that lobectomy must be the surgical procedure of choice even for patients with early lung cancer because higher locoregional recurrence and death rate are associated with limited resection. ${ }^{14}$ This report considered segmentectomy and wedge resection as a limited resection; therefore, its assessment of segmentectomy is somewhat confused. In fact, several authors report that segmentectomy can be an alterative to lobectomy for treatment of early small lung cancer if patients are carefully selected. ${ }^{15-17}$ In our series, no patient in our limited group died as a result of recurrence and only 1 patient experienced local recurrence in another lobe, which was successfully resected. Also, no patient died as a result of a lung cancer recurrence. Thus, sleeve segmentectomy is feasible for carefully selected patients with early central tumor. A small tumor at the segmental bronchus without nodal involvement can be a good candidate for treatment by sleeve segmentectomy.

\section{Conclusions}

Sleeve lung resection can achieve local tumor control and long-term survival with low mortality and few anastomotic complications. Nodal status significantly affects long-term survival. Limited and extended resections are also feasible with local and long-term results comparable to those of standard sleeve lobectomy.

\section{References}

1. Okada M, Yamagishi H, Satake S, Matsuoka H, Miyamoto Y, Yoshimura M, et al. Survival related to lymph node involvement in lung cancer after sleeve lobectomy compared with pneumonectomy. J Thorac Cardiovasc Surg. 2000;119(4 Pt 1):814-9.

2. Ludwig C, Stoelben E, Olschewski M, Hasse J. Comparison of morbidity, 30-day mortality, and long-term survival after pneumonectomy and sleeve lobectomy for non-small cell lung carcinoma. Ann Thorac Surg. 2005;79:968-73.

3. Lausberg HF, Graeter TP, Wendler O, Demertzis S, Ukena D, Schafers HJ. Bronchial and bronchovascular sleeve resection for treatment of central lung tumors. Ann Thorac Surg. 2000;70:367-71.

4. Ferguson MK, Lehman AG. Sleeve lobectomy or pneumonectomy: optimal management strategy using decision analysis techniques. Ann Thorac Surg. 2003;76:1782-8.

5. Tronc F, Gregoire J, Rouleau J, Deslauriers J. Long-term results of sleeve lobectomy for lung cancer. Eur J Cardiothorac Surg. 2000;17: 550-6.

6. Okada M, Tsubota N, Yoshimura M, Miyamoto Y, Matsuoka H, Satake S, et al. Extended sleeve lobectomy for lung cancer: the avoidance of pneumonectomy. J Thorac Cardiovasc Surg. 1999;118: 710-3.

7. Bagan P, Berna P, Pereira JC, Le Pimpec Barthes F, Foucault C, Dujon A, et al. Sleeve lobectomy versus pneumonectomy: tumor characteristics and comparative analysis of feasibility and results. Ann Thorac Surg. 2005;80:2046-50.

8. Yildizeli B, Fadel E, Mussot S, Fabre D, Chataigner O, Dartevelle PG. Morbidity, mortality, and long-term survival after sleeve lobectomy for non-small cell lung cancer. Eur J Cardiothorac Surg. 2007;31:95-102. 
9. Mountain CF. Revisions in the International System for Staging Lung Cancer. Chest. 1997;111:1710-7.

10. Okada M, Nishio W, Sakamoto T, Uchino K, Yuki T, Nakagawa A, et al. Sleeve segmentectomy for non-small cell lung carcinoma. J Thorac Cardiovasc Surg. 2004;128:420-4.

11. Van Schil PE, Brutel de la Riviere A, Knaepen PJ, van Swieten HA, Reher SW, Goossens DJ, et al. Long-term survival after bronchial sleeve resection: univariate and multivariate analyses. Ann Thorac Surg. 1996; 61:1087-91.

12. Mehran RJ, Deslauriers J, Piraux M, Beaulieu M, Guimont C, Brisson J. Survival related to nodal status after sleeve resection for lung cancer. J Thorac Cardiovasc Surg. 1994;107:576-82.

13. Naruke T, Tsuchiya R, Kondo H, Asamura H. Prognosis and survival after resection for bronchogenic carcinoma based on the 1997 TNM- staging classification: the Japanese experience. Ann Thorac Surg. 2001;71:1759-64.

14. Ginsberg RJ, Rubinstein LV. Randomized trial of lobectomy versus limited resection for T1 N0 non-small cell lung cancer. Lung Cancer Study Group. Ann Thorac Surg. 1995;60:615-22.

15. Yoshikawa K, Tsubota N, Kodama K, Ayabe H, Taki T, Mori T. Prospective study of extended segmentectomy for small lung tumors: the final report. Ann Thorac Surg. 2002;73:1055-8.

16. Okada M, Koike T, Higashiyama M, Yamato Y, Kodama K, Tsubota N. Radical sublobar resection for small-sized non-small cell lung cancer: a multicenter study. J Thorac Cardiovasc Surg. 2006;132:769-75.

17. Schuchert MJ, Pettiford BL, Keeley S, D'Amato TA, Kilic A, Close J, et al. Anatomic segmentectomy in the treatment of stage I non-small cell lung cancer. Ann Thorac Surg. 2007;84:926-32. 